\title{
A POLÍTICA DE IDENTIDADES NA SOCIOLINGÜÍSTICA QUANTITATIVA E NA GEOLINGÜÍSTICA MONODIMENSIONAL: O INFORMANTE
}

(The politcs of identities in the quantitative sociolinguistics and in the monodimensional geolinguistics: the informer)

Maria Isabel Borges ${ }^{1}$

(Universidade Federal de Santa Catarina - UFSC)

\begin{abstract}
RESUMO: Neste trabalbo, procuramos apontar alguns aspectos das políticas de identidades e de representação em torno da figura do informante, em estudos feitos a partir das bases de dados do VARSUL (Variação Lingüistica Urbana na Região Sul do Brasil) e do ALERS (Atlas Lingüístico-etnográfico da Região Sul do Brasil). Na primeira base de dados, os pressupostos teóricos e metodológicos são da sociolingüística quantitativa enquanto, na segunda base de dados, os pressupostos teóricos e metodológicos são da geolingüística monodimensional. Nossa base teórica é constituída, principalmente, pelos trabalhos de Rajagopalan (1998; 2003), Hall (1996; 2003) e Bauman (2000; 1997; 1998). Foi possivel, assim, observar como a lingua e o informante são representados.
\end{abstract}

PALAVRAS-CHAVE: política de identidades; política de representação; informante; variação lingüistica.

ABSTRACT: In this work, we attempt to point some aspects of the politics of identities and of representation around the figure of the informer, in studies done starting from the bases of data of VARSUL (Urban Linguistic Variation in the South Area of Brazil) and of ALERS (Linguistic-Etnographic Atlas of the South Area of Brazil). In the first database, the theoretical and methodological assumptions are of the quantitative sociolinguistics while, in the second database, the theoretical and methodological assumptions are of the monodimensional geolinguistics. Our theoretical base is constituted mainly by of the studies of Rajagopalan (1998; 2003), Hall (1996; 2003) and

1 Doutoranda em Lingüística, Universidade Federal de Santa Catarina (UFSC) e bolsista do Conselho Nacional de Pesquisa (CNPq). 
Bauman (2000; 1997; 1998). Thereby, it was possible to observe as the language and the informer are representated.

KEY-WORDS: politics of identities; politics of representation; informer; linguistic variation.

\section{Considerações Iniciais}

$\mathrm{Na}$ década de 60, emergiram três movimentos teóricos que visavam questionar duas idéias fundamentais chomskyanas: 1) a existência de uma comunidade lingüística homogênea e 2) a existência de um falante-ouvinte ideal. Tais movimentos vieram a constituir em três áreas voltadas aos estudos da variação lingüística: 1) a sociologia da linguagem, representada por Joshua Fishman; 2) a etnografia da fala, liderada por Dell Hymes; e 3) a sociolingüística, encabeçada por William Labov.

A partir da idéia de falante-ouvinte ideal, de um lado, propôs-se a figura de um falante-ouvinte real: o informante. E de outro, os aspectos sociais e culturais da identidade do informante foram trazidos à baila, com o propósito de estudar a língua como um objeto da lingüística, constituído por um sistema de regras variáveis. A variação, segundo os estudos variacionistas, não concebe a língua como uma estrutura sem unidade. Trata-se de uma unidade que se dá em meio à heterogeneidade, e não, em meio à homogeneidade.

A proposta dos estudos acerca da variação lingüística, em princípio, parece revolucionária, contudo, por trás dos pressupostos teórico-metodológicos da sociolingüística quantitativa ${ }^{2}$ e da geolingüística monodimensional $^{3}$ - subáreas da lingüística advindas dos três movimentos teóricos supracitados - possuem suas preferências quanto ao perfil do informante. Aquela prefere um informante da zona urbana e esta, da zona rural (Margotti 2004b).

Neste trabalho, pretende-se mostrar que o perfil do informante das duas subáreas da lingüística em questão camufla uma política excludente

\footnotetext{
2 Trata-se de uma subárea da lingüística baseada nos trabalhos de Labov.

3 Trata-se de uma subárea da lingüística, que conjuga a dimensão espacial com os fundamentos teórico-metodológicos labovianos.
} 
das práticas identitárias do sujeito acerca da língua da qual faz uso. Tais estudos não consideram as atitudes do sujeito em torno de sua língua, sob o ponto de vista político-ideológico; pode-se argumentar que há uma hierarquização a qual se privilegia a fala do informante: o produto individual gerado, em especial, durante a coleta de dados, e não, os comentários acerca da língua que o informante possa fazer.

Foram analisadas, para a realização deste trabalho, as políticas de identidades e de representação em torno da figura do informante, em estudos feitos a partir das bases de dados do VARSUL (Variação Lingüüstica Urbana na Região Sul do Brasil) e do ALERS (Atlas Lingüístico-etnográfico da Região Sul do Brasil). Os estudos relacionados à primeira base de dados foram publicados em duas revistas científicas: Letras de Hoje (2000, volume 35, número 1) e Organon (2000, volume 14, números 28 e 29); e os relacionados à segunda base de dados advêm de diferentes publicações: Altenhofen (2000, 2002, 2004), Margotti (1991, 2004a), Margotti e Vieira (2006).

Além disso, as políticas de representação e de identidades configuradas tanto na sociolingüística quantitativa quanto na geolingüística monodimensional foram postas em foco, neste trabalho, porque constituem os paradigmas teórico-metodológicos norteadores das bases de dados em questão respectivamente: VARSUL e ALERS.

\section{Base Teórica}

\subsection{Política de representação}

Quando se discutem questões sobre política, Bauman (2000: 27) afirma que "... a grande questão não é o que deve ser feito, mas quem tem o poder e decisão para fazer". O autor argumenta que não há uma distinção entre público e privado, na pós-modernidade ${ }^{4}$, e sim, uma transição entre

\footnotetext{
4 Com base em Peters (2000: 9), a concepção de pós-modernismo relaciona-se a um "objeto teórico": o modernismo vincula-se ao paradigma estruturalista e pós-modernismo, ao pós-estruturalista. Aquele possui duas concepções: a primeira denota um movimento estético e/ou artístico, iniciado no final do século XIX. Enquanto a segunda está relacionada à idéia de período, de momento histórico e filosófico, “... significando 'modernidade' — a época que se segue à época medieval. ... o 'moderno' envolve uma ruptura autoconsciente com o velho, o clássico e o tradicional, e uma ênfase
} 
estas duas dimensões. $\mathrm{Na}$ modernidade, o sujeito sacrificou sua liberdade em troca da "segurança", da "certeza" e da "garantia". Estes três itens, que foram trocados pela liberdade, resumem, segundo Bauman (2000), o termo alemão "sicherbeit", utilizado por Freud, nos anos 70, ao escrever $O$ malestar na civilização.

Bauman (2000: 24) argumenta que Freud, nos anos 70, estava se referindo à "civilização moderna e ocidental" da década de 1920. Tal referência ignorava a existência de qualquer civilização diferente da ocidental, centralizada no oeste europeu. Porém, na pós-modernidade, admite-se a multiplicidade de civilizações em convivência com a ocidental e sem hierarquia de valores. Para Bauman (2000), nas civilizações inseridas na pósmodernidade, o sujeito pós-moderno (essa noção será discutida mais adiante) não mais troca sua liberdade pela "segurança", pela "certeza" e pela "garantia", como ocorreu na modernidade, conforme os escritos dos anos 70, de Freud. Ao invés disso, há a inversão, de forma que o sujeito pós-moderno troca sua segurança (incluindo a certeza e a garantia) pela liberdade na pós-modernidade.

Dessa forma, as incertezas e as dúvidas são fabricações sociais necessárias para a existência de um modo de viver, cabe ao sujeito pós-moderno conviver e se conformar com elas. Tal convivência e conformidade não propiciaram ao sujeito pós-moderno alcançar a felicidade ou a oportunidade de desfrutar somente os prazeres da liberdade, em vez disso, ele adquiriu também outras inquietações.

O sujeito pós-moderno acreditou na possibilidade de ter tudo, de gozar de todos os prazeres e desejos, mas se esqueceu que a completude, aliás, a plenitude seria impossível. Mais uma vez, segundo Bauman (1998a e 1998b), o sujeito pós-moderno continua insatisfeito, porque ele acreditou na possibilidade de ganhar tudo, sem nada perder: "não há nenhum ganho sem perda” (Bauman 1998a: 10); e, além disso, não é possível garantir um

concomitante no novo e no presente" (PETERS, 2000: 12). A modernidade é iniciada com o modo de pensar de René Descartes, na França, e de Francis Bacon, na Inglaterra (Peters 2000). Quando se fala de pós-modernidade, está-se referindo à segunda concepção de modernismo. Constitui uma periodicidade histórica e filosófica e uma releitura problematizadora das idéias do estruturalismo, colocando-o como objeto de reflexão e apontando uma relação com o modo de pensar pós-estruturalista. 
"estado de satisfação" (Bauman 1998a: 10) quando se adquire a liberdade, na pós-modernidade.

Ainda com Bauman (1998b), seria possível assegurar a liberdade do sujeito pós-moderno, pautada na ética pós-moderna (Bauman 1997), se construirmos uma comunidade fundada em três princípios: "Liberdade", "Diferença" e "Solidariedade".

Uma política inspirada pela sabedoria pós-moderna só pode ser orientada para a reafirmação do direito de os indivíduos livres se assegurarem e perpetuarem as condições da sua liberdade.

A política pós-moderna, voltada, para a criação de uma comunidade política viável, precisa ser guiada... pelo tríplice princípio de Liberdade, Diferença e Solidariedade, sendo a solidariedade a condição necessária e a contribuição coletiva essencial para o bem-estar da liberdade e diferença (Bauman 1998b: 256).

Para Bauman (1998b), a negociação, propiciada pela política, é o que possibilitaria a solidariedade e, por conseqüência, uma "liberdade segura". Assim, com base nos estudos de Bauman (1997, 1998a, 1998b, 2000), não se pode falar de "bem público", porque, no lugar da separação e da legitimação de pares em oposição - como bem e mal, público e privado, interno e externo, aberto e fechado, justo e injusto, moral e imoral, língua e fala, natureza e cultura, fato e valor, arte e ciência, racionalidade e irracionalidade, dentre várias outras dicotomias -, passou-se a admitir a fluidez, a transição, a mutabilidade e o jogo, em função do desmascaramento do instituído véu da fixidez, da estabilidade, da imutabilidade e da estrutura. Torna-se, portanto, impossível definir o que é bem público e o que é bem privado. Pode-se dizer que, no lugar de público e de privado, há o jogo, a negociação no interior de uma "comunidade política", segundo Bauman (1998b).

Detendo-se à articulação da política com a língua(gem), Rajagopalan (2003) argumenta que a linguagem como sistema de representação, e a política, como "apresentação", "são apenas duas faces de uma mesma moeda” (Rajagopalan 2003: 32). A linguagem e a política se articulam e coabitam uma mesma posição, assim como a representação se articula, simultaneamente, com a linguagem e com a política.

... a tese do representacionalismo é, ao mesmo tempo, uma questão política e lingüística - ou, quem sabe, política por ser lingüística e lingüística por ser política. Em outras palavras, segundo essa análise - por sinal, a que me parece mais interes- 
sante e capaz de explicar uma série de outras questões pendentes - a questão lingüística e a questão política seriam uma só (Rajagopalan 2003: 32).

A linguagem e a política interconectam-se, porque a representação lingüístico-política ocupa a posição de um outro ausente. Esse outro ausente atribui-lhe o poder de circunscrever-se sócio-historicamente e de configurar-se, de maneira a testemunhar e a marcar uma presença ausente. Dito de outra maneira, quando há representação lingüístico-política, tomase uma posição não-arbitrária e sempre circunscrita em uma ordem sóciohistórica, cuja função é presentificar um quem ou um quê não-presentes o outro ausente -, constituindo a política de representação. Tal política de representação não se fundamenta na determinação, pelo contrário se constitui sempre na combinação de um posicionamento em função dos aspectos sócio-históricos e também na concepção de "apresentação", de maneira a haver uma representação em nome de alguém (Rajagopalan 2003).

Rajagopalan (2003) salienta a dificuldade em se perceber o caráter politizante da linguagem, já que a própria linguagem ainda é vista como algo neutro, natural, especialmente, sob o ponto de vista de teóricos defensores das idéias estruturalistas e gerativistas. Ainda com relação ao caráter politizante da linguagem, Rajagopalan (2003: 33) afirma que há o envolvimento de escolhas, porque "a questão da escolha é geralmente reconhecida como questão-chave quando se discute política”. Contudo, a partir do envolvimento de escolhas, uma política de representação pressupõe a questão ética por meio de julgamentos de valor. Ou seja, as escolhas são feitas, visto que se classifica, por intermédio da linguagem, a realidade social, a fim de se posicionarem em função de uma política que represente interesses, conveniências, relações de poder e de dominação.

... a ética, e portanto toda atividade que envolve a política, envolve escolha. E a escolha pressupõe a existência de uma escala de valores, uma hierarquia. A questão da representação é uma questão política precisamente por envolver escolha. O difícil no caso é enxergar a presença da escolha quando o assunto é a representação lingüística. A tentação é pensar que é a linguagem que represente o mundo, sendo que nós, enquanto usuários da língua, estamos inteiramente à mercê das representações que nossa linguagem nos impõe (Rajagopalan 2003: 33-34).

Instala-se um jogo ético-político (Borges 2004) quando há, de um lado, escolhas feitas por sujeitos, por intermédio da linguagem e, por outro 
lado, há influências da linguagem sobre os sujeitos, de forma a interferir no processo de (re)configuração das identidades pós-modernas, constituindo uma política de identidades. Os sujeitos pós-modernos, por meio da linguagem, atuam, ocupando posições circunscritas sócio-historicamente, de maneira a reivindicar, a assumir e a negar identidades. Por trás dessa atuação dos sujeitos pós-modernos, há intervenções sobre a linguagem e, ao mesmo tempo, essa linguagem intervém sobre esses sujeitos. Dessa maneira, a noção de representação, no cerne da linguagem, não constitui um reflexo, um espelho, em vez disso se trata de uma atribuição/produção de sentidos, deslocamentos incessantes de significantes por meio de atos ético-políticos, de atos de fala e de atos de nomeação/predicação, visto que "toda representação é política porque se constitui num ato de intervenção" (Rajagopalan 2003: 120).

\subsection{Politica de identidades}

A política de identidades ocorre na e pela linguagem, o que nos leva a re-pensar a noção de identidade(s) lingüística(s), deslocando as transformações sofridas na pós-modernidade. Segundo Rajagopalan (1998), as concepções essencialistas e tradicionais de identidade lingüística ainda norteiam os estudos sobre a linguagem, apesar de os deslocamentos teóricos, conceituais e metodológicos terem ocorrido e continuem a ocorrer em outras áreas de conhecimento, impulsionando transformações. "É chegada a hora para uma reconsideração radical?” (Rajagopalan 1998: 21). A língua(gem) constitui um palco de transformações identitárias do sujeito o qual faz uso dela, mas também é por ela usado constantemente. O sujeito (re)constrói suas identidades lingüísticas, de forma a assumir, negar e reivindicar posições na e por meio da língua(gem).

na língua e através dela. Isso significa que o indivíduo não tem uma identidade fixa anterior e fora da língua. Além disso, a construção da identidade de um indivíduo na língua e através dela depende do fato de a própria língua em si ser uma atividade em evolução e vice-versa. Em outras palavras, as identidades da língua e do indivíduo têm implicações mútuas. Isso por sua vez significa que as identidades em questão estão sempre num estado de fluxo (Rajagopalan 1998: 41-42).

Pensar a identidade lingüística, sob esse viés, convoca os estudos lingüísticos a re-formularem seus propósitos e suas metodologias, proble- 
matizando suas fundamentações teóricas, deslocando visões restritas, fragmentando a ilusória homogeneidade e a ilusória fixidez lingüísticas. Com isso, o sujeito é visto de modo fragmentado, mas, ao mesmo tempo, abrese às possibilidades propiciadas pela língua(gem), (re)configurando-se sempre na heterogeneidade.

Hall (2003) sintetizou três formas de identidades que os sujeitos assumiram ao longo dos tempos: sujeito do Iluminismo, sujeito sociológico e sujeito pós-moderno, que se baseiam na imbricação entre identidade e sujeito. O conceito de identidade do sujeito do Iluminismo é efeito da idéia de centralidade.

O sujeito do Iluminismo estava baseado numa concepção da pessoa humana como um indivíduo totalmente centrado, unificado, dotado das capacidades de razão, de consciência e de ação, cujo "centro" consistia num núcleo interior, que emergia pela primeira vez quando o sujeito nascia e com ele se desenvolvia, ainda que permanecendo essencialmente o mesmo - contínuo ou "idêntico" a ele - ao longo da existência do indivíduo (Hall 2003: 10-11).

A complexidade do mundo moderno e a constatação de que a essência do sujeito mantinha uma relação externa - negando a sua autonomia e auto-suficiência -, refletiu na idéia de um sujeito sociológico. A cultura fazia a mediação entre "os valores, sentidos (...) símbolos dos mundos" (Hall 2003: 11) e o centro do eu, por meio de uma "interação". Essa concepção foi defendida pelos interacionistas simbólicos G. H Mead, C. H. Cooley e outros.

Descrevemos uma concepção de identidade baseada na essência e outra, "na 'interação' entre o eu e a sociedade" (Hall 2003: 11), porém o processo de identificação do sujeito perdeu seus caracteres de unidade e estabilidade para sofrer uma fragmentação constante, tornando-se "mais provisório, variável e problemático" (Hall 2003: 12). Esse processo de identificação, que não permite a fixidez de uma essência humana, caracteriza o sujeito pós-moderno. Ou seja, a identidade do sujeito pós-moderno se forma e se transforma de maneira descontínua, estando sempre móvel. É por intermédio dessa mobilidade constante que:

o sujeito assume identidades diferentes em diferentes momentos, identidades que não são unificadas ao redor do "eu" coerente. Dentro de nós há identidades contraditórias, empurrando em diferentes direções, de tal modo que nossas identificações 
estão sendo continuamente deslocadas(...). A identidade plenamente unificada, completa, segura e coerente é uma fantasia. Ao invés disso, à medida em que (sic) os sistemas de significação e representação cultural multiplicam, somos confrontados por uma multiplicidade desconcertantes e cambiantes de identidades possíveis, com cada uma das quais poderíamos nos identificar - ao menos temporariamente (Hall 2003: 13).

A crescente multiplicação dos "sistemas de significação e representação cultural" implica o aumento das possibilidades de assumir, negar e reivindicar identidades diferentes a cada circunstância deparada. Por outro lado, Rajagopalan (2002) desloca a noção de identidades do sujeito pósmoderno (Hall 2003), a fim de considerá-la como "um construto [...] como algo em constante processo de (re)construção” (Rajagopalan 2002: 77). Não há, portanto, um processo de identificação baseado no desenvolvimento teleológico, e sim, uma mobilidade em constante (re)construção [no sentido de uma (re)configuração].

Hall (1996), em um trabalho anterior, ao discutir de que modo a identidade é construída, compara o sujeito do pós-colonialismo ao cinema, pois este se vincula à fotografia, à imagem estática, ao movimento, ao fluxo. $\mathrm{O}$ sujeito pós-colonial refere-se, sobretudo, aos sujeitos que sofreram, direta ou indiretamente, as conseqüências do colonialismo. O colonialismo não constitui o modelo social-político-econômico atualmente, contudo os sujeitos "descendentes" dessa época se configuram como pós-coloniais por estarem em busca de uma identidade "própria", no lugar daquela construída pelos colonizadores. Essa busca identitária, por parte dos sujeitos póscoloniais, constitui também um dos desejos norteadores das identidades locais, étnicas e nacionalistas. Para Hall (1996), as identidades vinculamse à noção de representação.

As práticas de representação implicam sempre em posições de onde se fala ou se escreve - as posições de enunciação. As teorias sobre enunciação mais recentes sugerem que, não obstante falarmos, por assim dizer, "em nosso nome”, de nós mesmos e com base em nossa própria experiência, quem fala e a pessoa de quem se fala nunca são idênticos, nunca estão exatamente no mesmo lugar (Hall 1996: 68).

A cada posição assumida, o sujeito desempenha, representa uma função, pois, para aquela posição, determinadas atitudes tornam possível sua identificação pelo fato de não se agir de outra maneira. Por isso, "a identi- 
dade não é tão transparente ou tão sem problemas como nós pensamos. (...) deveríamos pensá-la, talvez, como uma 'produção' que nunca se completa, que está sempre em processo...” (Hall 1996: 68). Essa ilusória transparência em torno das identidades camufla o fluxo de posições tomadas. "Todos nós escrevemos e falamos desde um lugar e um tempo particulares, desde uma história e uma cultura que nos são específicas. $\mathrm{O}$ que dizemos está sempre 'em contexto', posicionado" (Hall 1996: 68).

No processo de identificação, o sujeito posiciona-se em um local, o qual manifesta um sentimento de pertença, (re)construindo sua identidade cultural. Esse local refere-se a uma região, a um país, a uma comunidade, a um "desde" que Hall (1998: 68) aponta como posição "contextualizadora". Não (re)construímos nossas identidades do nada, do vazio, e sim, a partir de um viés posicional, perpassado pela história, pela cultura, pelo social, pelo político e pelo ideológico.

Longe de fixas eternamente em algum passado essencializado, estão sujeitas ao contínuo "jogo" da história, da cultura e do poder. As identidades, longe de estarem alicerçadas numa simples "recuperação" do passado, que espera para ser descoberto e que, quando o for, há de garantir nossa percepção de nós mesmos pela eternidade, são apenas os nomes que aplicamos às diferentes maneiras que nos posicionam, e pelas quais nos posicionamos, nas narrativas do passado (Hall 1996: 69).

As nomeações apontam diferentes lugares em que os sujeitos estão (re)configurando suas identidades. Elas são efeitos, construtos de um movimento da história, cultura e do poder; ressignificam as diferentes nomeações, porque, por trás delas, outros valores lhes são atribuídas. A (re)configuração de identidades (política de identidades) constitui um fluxo, de maneira que o sujeito se torna e atua como um estrategista, um jogador de identidades (BORGES, 2004). As regras do jogo e o próprio jogo impulsionam o sujeito a escolher a identidade a ser assumida, em uma determinada situação. Em função dessa assunção, o sujeito (re)constrói sua identidade, de forma simultânea, a partir de uma mesmidade e de uma outridade, mas sempre no bojo de uma política de representação (Rajagopalan 2002 e 2003) ou no cerne de sistemas de significação e representação (Hall 1996; 2000; 2003).

Rolnik (1997) argumenta que a (re)construção das identidades não se reduz a dois pólos em oposição: "o enrijecimento de identidades locais e a ameaça de pulverização total de toda e qualquer identidade” constituem 
"um falso problema" (Rolnik 1997: 23). Trata-se de abandonar o vício de identidade fixa, única.

O que se coloca para as subjetividades hoje não é a defesa de identidades locais contra identidades globais, nem tampouco da identidade em geral contra a pulverização; é a referência identitária que deve ser combatida, não em nome da pulverização (o fascínio niilista pelo caos), mas para dar lugar aos processos de acontecimentos. Recolocado o problema nesses termos, reivindicar identidade pode ter o sentido conservador de resistência a embarcar a tais processos (Rolnik 1997: 23).

A reivindicação de identidades consiste em uma "válvula de escape", pautada no ato de resistir sempre a todo sistema fechado ou processo, cujo propósito é a completude, a totalidade e o fechamento. Trata-se de resistir a tudo o que quer capturar o sujeito, prendê-lo por meio da força ideológica e política. Segundo Rolnik (1997), "todas... estratégias, tanto as que visam à volta às identidades locais quanto as que visam à sustentação das identidades globais, têm uma mesma meta: domesticar as forças" (Rolnik 1997: 24).

$\mathrm{Na}$ Lingüística, essa domesticação das forças constitui um processo frágil, segundo Rajagopalan (1998). As tentativas de captura do sujeito falante - enquadrando-o como consciente, controlador de todo o seu dizer, ou como sujeito falante idealizado, que jamais erra sob os parâmetros lingüísticos gerativistas - sofreram deslocamentos teóricos e metodológicos. Segundo Rajagopalan (1998 e 2003), não é possível pensar o sujeito da linguagem como postularam as teorias estruturalistas e as teorias gerativistas. Mas, por outro lado, a persistência em pensar, teorizar e enquadrar tanto o sujeito, como a língua(gem) dessa maneira ainda perpassa vários estudos lingüísticos.

Permanece o fato, porém, de que os lingüistas até agora têm sido lentos em perceber todo o alcance das implicações do multilingüismo e do multiculturalismo. Em conseqüência disso, não chegaram normalmente a reconhecer que o conceito tradicional de identidade em lingüística necessita de revisão urgente. A identidade individual como algo total e estável já não tem nenhuma utilidade prática num mundo marcado pela crescente migração das massas e pela entremesclagem cultural, religiosa e étnica, numa escala sem precedentes (Rajagopalan 1998: 40).

A revisão da concepção de identidade lingüística constitui uma evidente e urgente necessidade, uma vez que se trata de uma noção baseada 
no fluxo de deslocamentos constantes. Além disso, não se pode mais pensar que o sujeito informante apenas se constitui como um falante-ouvinte real de uma língua, sendo importante para os estudos lingüísticos (especialmente à sociolingüística e à geolingüística) somente o que dizem em sua língua materna. Ignora-se, como argumenta Rajagopalan (1998 e 2003), o que o sujeito falante diz sobre sua língua e como se constitui identitariamente por meio dela.

\section{Discussão}

É importante destacar que um dos fundamentos teórico-metodológico deste trabalho é a articulação entre linguagem e política. Dessa articulação, configuram-se formas de representar lingüístico-politicamente e a língua não é posta à margem disso. Ela constitui um meio do sujeito fazer suas escolhas não-arbitrárias. Ou seja: a língua consiste numa forma do sujeito atuar eticamente, sem desconsiderar o que está a seu redor.

Conforme os artigos produzidos, com base nos dados coletados nos projetos VARSUL e ALERS, a língua é vista como um objeto heterogêneo e variável, que assume um caráter essencialmente social.

A atenção sociolingüística está concentrada na heterogeneidade dentro dos sistemas lingüísticos. A limitação da pesquisa à variação intrassistêmica em sociolingüística deve era explicada primeiramente como uma reação contra a idealização explícita que era típica da abordagem gerativa clássica da língua como um sistema homogêneo. O mérito da sociolingüística não é tanto porque acentua a heterogeneidade dos sistemas lingüísticos, mas antes porque desenvolveu técnicas essencialmente quantitativas capazes de revelar a ordem que existe na heterogeneidade (Hinskens, F.; Hout R. v; W. Leo Wetzels 2000: 20). (1)

Ao falar, um indivíduo não apenas transmite uma mensagem neutra contida em seu discurso (Appel; Muysken 1992: 11), mas também normas e valores culturais que permitem a um interlocutor atento depreender uma série de informações a respeito desse indivíduo e do grupo social a qual pertence. Se a língua tem significado social, as pessoas avaliarão isto em relação ao status social de seus usuários. Suas atitudes lingüísticas serão atitudes sociais (Margotti, 2004b, meio eletrônico) (2) ${ }^{6}$.

\footnotetext{
5 O número (1) significa que se trata de um artigo científico atrelado ao projeto VARSUL.
}

6 O número (2) significa que se trata de um artigo científico atrelado ao projeto ALERS. 
A relação da língua com o social constitui uma forma de representar, que visa opor-se à idéia estruturalista e gerativista (outra representação) de concebê-la: objeto homogêneo e formal. Não é propósito nem da sociolingüística quantitativa e nem da geolingüística monodimensional desvincular a concepção de língua da idéia de sistema. Ambas valorizam a variação da língua, no entanto aquela prioriza a "heterogeneidade dentro dos sistemas lingüísticos” (Hinskens, F.; Hout R. v; W. Leo Wetzels, 2000: 20) e esta a heterogeneidade no espaço, contrapondo entre si os diversos dialetos ${ }^{7}$.

Num primeiro momento, as formas de representar conceitualmente a língua, sob o olhar da sociolingüística quantitativa quanto o da geolingüística monodimensional, em princípio, apresentam-se claras. Contudo, a clareza é aparente, pois a ambigüidade norteia as análises das variações lingüísticas postas como dados. Um dos fundamentos dos estudos variacionistas é a oposição ao modo racionalista de observar e analisar a língua. Sob os pontos de vista gerativista - sobretudo - e estruturalista (Saussure concebia a língua como uma operação aritmética) ${ }^{8}$. Apesar dessa assumida contraposição, na sociolingüística quantitativa e na geolingüística monodimensional, analisam-se quantitativamente os dados coletados. Utilizamse programas computacionais e são feitas tabulações e gráficos, convertendo os dados em porcentagens. Em todos os artigos analisados, neste estudo, as análises seguem princípios quantitativos.

Pode-se dizer que se é unânime a análise quantitativa das variações lingüísticas percebidas nos sistemas lingüísticos, então a língua é uma heterogeneidade cuja variação segue a ordem matemática: a regularidade revelada em meio à diversidade. Em outras palavras: quantificam-se as variações lingüísticas, e em seguida, verificam-se as hipóteses levantadas, para construir-se a explicação das razões das ocorrências de variação. Busca-se a regularidade da variação, pois se argumenta que não há aleatoriedade. A heterogeneidade é motivada por fatores exteriores ao sistema lingüístico. Quantificar as variações lingüísticas pode possibilitar visualizálas panoramicamente, no entanto, em trabalhos cuja abordagem é qualitati$\mathrm{va}^{9}$, se critica o uso excessivo de instrumentos quantitativos, principalmente

\footnotetext{
Segundo Margotti (2004a), não há um consenso entre os estudiosos em torno do conceito de dialeto: alguns o vinculam à habilidade do sujeito e outros, às questões sociais.

8 Conferir Lopes da Silva (2001).

9 Conferir BAUER e GASKELL (2005).
} 
quando a análise e a discussão dos dados coletados se limitam à quantificação. Assim, pressupõe-se que os dados falam por si mesmos.

Para tanto, em cada subárea da lingüística - a sociolingüística quantitativa e a geolingüística monodimensional -, apresentam-se os elementos extralingüísticos que atuam como impulsores da variação. $\mathrm{Na}$ sociolingüística quantitativa, com base nos trabalhos pioneiros de Labov, elegemse a idade, o sexo e a escolaridade como fatores sociais interventores da mudança lingüística. A partir deles, em cada subárea, há uma política de nomeação/predicação diferenciada (Tabela 1):

\begin{tabular}{|c|c|}
\hline Sociolingüística quantitativa & Geolingüística monodimensional \\
\hline $\begin{array}{c}\text { Variáveis extralingüísticas ou } \\
\text { sociais }\end{array}$ & Dimensões extralingüísticas ou sociais \\
\hline idade & diageracional \\
\hline sexo & diagenérica \\
\hline escolaridade & diastrática \\
\hline \multirow{2}{*}{} & diafásica: variação de estilo de fala \\
\cline { 2 - 2 } & diatópica: variação de espaço \\
\cline { 2 - 2 }
\end{tabular}

Tabela 1: As variáveis da sociolingüística quantitativa e da geolingüística monodimensional

Percebe-se que a língua é representada como um objeto constituído no entremeio de elementos internos e externos. Dito de outra forma, ela se constitui na interação entre o que é definido como lingüístico e o que é denominado como extralingüístico: o social. Assim, pode-se dizer que a nomeação "extralingüística" qualifica, separando em dois extremos ou pontos distintos: o lingüístico e o social. Apesar da sociolingüística quantitativa e da geolingüística monodimensional conceber a língua como parte integrante do contexto social, tais disciplinas implicitamente se fundamentam na distinção do objeto de estudo de seu meio social da qual se circunscreve. Pode-se confirmar esse argumento quando se observa o uso do adjetivo "heterogêneo" ou do substantivo "heterogeneidade" nos trabalhos analisados.

A sociolingüística variacionista, como ramo específico da ciência lingüística, consolida-se de uma concepção de linguagem essencialmente social, que trata a língua como correlacionada de forma sistemática com a história social dos falantes. A partir 
dessa concepção, a heterogeneidade (diversidade) lingüística se constitui em propriedade inerente ao próprio sistema lingüístico, entende-o como aquele manifesto no uso real de falantes reais em processo de comunicação.

Partindo dos empregos concretos da língua falada e focalizando como estudo a variação lingüística, concebendo-a como um princípio geral e universal das línguas, passível de ser descrita e analisada, a teoria sociolingüística pressupõe que toda variação é motivada, ou seja, controlada tanto por fatores internos ao sistema lingüístico quanto por fatores externos ao mesmo (Vazzata-Dias, 2000: 210) (1).

A discussão da relação entre língua e identidade étnica deve levar em conta, ainda, que a língua é uma realidade heterogênea, cuja variação estrutural no espaço geográfico, na ordem social e em suas funções (da língua) está em grande parte relacionada à história, às crenças e aos valores culturais e ideológicos da comunidade que a fala: relações de prestígio e poder, posição social e orientação cultural do falante etc. (Margotti, 2004b, meio eletrônico) (2).

Acredita-se na existência de uma comunidade lingüística heterogênea, contrapondo-se ao conceito gerativista de comunidade lingüística homogênea. Mais uma vez, trata-se de um par distinto - homogeneidade e heterogeneidade -, ao lado, é claro, de lingüístico e social, ou interior e exterior. Pode-se afirmar que a concepção de língua da sociolingüística quantitativa quanto a da geolingüística monodimensional pauta-se em alguns resquícios dos estudos tradicionais estruturalista e gerativista (princípio matemático e distinção entre objeto e meio, por exemplo) ${ }^{10}$ e na abertura para a agregação de constituintes sociais, de modo interativo, de trânsito entre oposições ou pontos colocados como separados.

Há dois aspectos relevantes a serem acrescentados à concepção de língua da sociolingüística quantitativa e da geolingüística monodimensional. O primeiro diz respeito à abordagem dos dados coletados e o segundo, ao modo de ver o falante. Por trás destes dois aspectos, confirma-se o argumento de que a definição de língua está condicionada mais ao passado do que ao presente ou ao futuro. Além disso, procura-se silenciar propositalmente aquele que é visto poucas vezes como falante e, na maioria das vezes, como mudo.

Já foi dito anteriormente que a análise dos dados coletados e armazenados em torno dos projetos VARSUL e ALERS baseia-se na quantificação. Tal procedimento justifica-se porque as técnicas quantitativas revelam

10 Conferir Borges (2004). 
a "ordem da heterogeneidade" (Hinskens, F.; Hout R. v; W. Leo Wetzels 2000: 20). Busca-se, com isso, uma regularidade lingüística, claramente identificável. No entanto, há outras abordagens metodológicas que também podem evidenciar a regularidade, sem apagar a subjetividade. Dito de outra maneira: construir uma representação na qual a língua é constituída de variações que seguem uma certa regularidade consiste numa política de representação, uma das característica dos estudos variacionistas como a sociolingüística quantitativa e a geolingüística monodimensional -, ao lado de outras possibilidades representacionais.

Com a análise quantitativa, dá-se voz àquilo que é mudo: o número ou a quantificação. A quantificação de falas, coletadas em circunstâncias específicas, é construída para que falantes exerçam o que sabem fazer: dizer ou falar uma língua. Durante a coleta de dados, o momento das entrevistas, os sujeitos de pesquisa são induzidos a produzirem falas que remetam a questões lingüísticas particulares. Dito de outra forma, o sujeito de pesquisa não pode dizer o que deseja. Pelo contrário, ele deve se submeter às regras de um jogo apresentadas pelo pesquisador: o entrevistador. Por exemplo, têm-se algumas dessas regras:

A amostra de cada município consiste de entrevistas feitas com 24 falantes. Num primeiro contato com o informante foi gravada a entrevista $A$, que contém informações sobre a identidade social do mesmo. Essa entrevista, com duração que varia de 5 a 15 minutos cada uma, não foi transcrita, mas usada para registro das informações sociais relevantes sobre o informante e para o planejamento de uma segunda entrevista. No segundo contato, foi gravada a entrevista B, com duração aproximada de 45 minutos, que contém uma conversa em estilo não controlado sobre a vida do habitante da cidade (VARSUL, meio eletrônico) (2).

A função do entrevistador é coletar falas, de acordo com regras específicas, as quais se configuram na forma de perguntas. Elas atuam como regras condutoras do que deve ser dito. Se o sujeito de pesquisa produzir falas que respondam as indagações propostas pelas perguntas ou que induzem a produzirem usos da língua, vistas pelo pesquisador como variações lingüísticas, então ele se configura como informante. Suas falas assumem a posição científica de dados da pesquisa. Porém, feito o deslocamento: a fala produzida por um sujeito falante - o pesquisado ou informante -, para objeto de estudo - o dado -, a subjetividade é silenciada. É, nesse instante, que o falante assume uma função cuja conveniência é o exercício da voz, do falar, do dizer, desde que esteja em conformidade com as regras estabeleci- 
das pelas perguntas e outras circunstâncias da entrevista e pelos papéis assumidos pelo pesquisador (ou entrevistador ou inquiridor) e pelo pesquisado (ou entrevistado ou inquirido ou informante). Aquele é o coletador das variações lingüísticas, a partir de uma intervenção política. O pesquisador possui a função de coletar determinados produtos lingüísticos que se enquadrem numa determinada visão teórico-metodológica. Em outras palavras, o dizer, devidamente produzido, segue uma política de representação específica, a qual se ancora numa política de nomeação/predicação particular: a terminologia.

Como foi visto antes, as nomeações atribuídas aos fatores extralingüísticos, apesar de se referirem ao mesmo elemento, são diferentes. Para a sociolingüística quantitativa, os fatores extralingüísticos são representações da idade, sexo e escolaridade, conforme a construção de uma regularidade das mudanças da língua no interior do sistema. Ou seja: tal construção é uma forma de representar a variação, a partir da interação entre o que é visto como interior e o que é visto como exterior à língua. Já para a geolingüística monodimensional, os fatores sociais seguem uma construção condicionada às dimensões espaciais, isto é, a política de representação fundamenta-se primeiramente no fator espacial, para em seguida, levar-se em conta a idade, o sexo e a escolaridade do falante. Desse modo, a diferença terminológica das duas subáreas da lingüística não consiste numa simples designação, e sim, numa escolha que pressupõe um julgamento de valor. Para aquela, a variação da língua, no interior de um sistema, é uma prioridade, enquanto para esta, a variação da língua, no espaço constitui seu foco.

Apesar da sociolingüística quantitativa e da geolingüística monodimensional se basearem nas diferenças de sexo, escolaridade e idade, e também na análise quantitativa, a primeira olha as mudanças da língua dentro de seu limite sistêmico e a segunda considera tais variações, relacionandoas com o espaço geográfico. Dessa forma, para a geolingüística monodimensional, não basta só a quantificação mas também a cartografia: a construção de mapas descritivos, articulando dialeto com espaço. A nítida diferença de um dialeto para outro é marcado por linhas imaginárias denominadas de isoglossas. Isto é, a terminologia diferencia uma disciplina de outra, e também visa designar ocorrências ou situações etc. necessárias, conforme os propósitos teórico-metodológicos. É interessante salientar que a terminologia de uma disciplina ou de uma área de conhecimento segue 
um processo de nomeação que qualifica ações, situações, fatos, sujeitos... Tal processo, quando se vincula a uma política de representação e a um modo de tratar o dado coletado, constitui uma das vigas sustentadoras desse processo de nomeação/predicação de uma dada disciplina ou área de conhecimento.

Após a coleta, o falante é silenciado, pois o dado diz o que o pesquisador quer saber ou averiguar no lugar daquele. Percebe-se tal silenciamento quando as análises das variações lingüísticas colocadas em discussão consistem numa mera explicação das tabulações das variáveis postas como dados de pesquisa. $\mathrm{O}$ dado produzido, sob determinadas condições e regras, é um construto que se personifica; é um objeto construído a partir do ponto de vista do pesquisador, em que se fala em nome de quem produziu "brutamente". Aquele dizer "bruto" é um objeto lapidado, pronto para ser quantificado e submetido às averiguações de hipóteses elaboradas por um pesquisador. A grosso modo, esquece-se do sujeito falante e também, durante a produção de um artigo científico, a presença do pesquisador é camuflada por meio de uma construção argumentativa aparentemente neutra: trata-se de um modo de representar o conhecimento científico produzido.

A ciência diz, e não, um sujeito cientista (função assumido pelo pesquisador), que se circunscreve no jogo da ciência (política de representação), diz/produz conhecimento. Em resumo: o conhecimento não se produz por si mesmo, o dizer não se transforma em dado sem a manipulação de um sujeito, sem o olhar dele, constituindo uma forma de representar por meio da linguagem. Por trás do silenciamento da subjetividade tanto no momento da coleta quanto no da análise e produção científica (artigos, teses, livros...), há a busca pela verdade. A construção teórico-metodológica, segundo essa política de representação, é mais verídica se for pautada num jogo argumentativo silenciador das vozes advindas do sujeito falante e do sujeito pesquisador, a ponto do dado se constituir uma evidência atrelada a uma objetividade. O próprio conceito de objetividade é questionável, pois algo se torna objetivo se alguém o olhar de determinada forma, ou seja, trata-se de um modo de representar, construído por um sujeito.

Quaisquer comentários que o sujeito falante produza a respeito da língua da qual fala não são considerados como dado, como objeto de análise. Tais comentários não assumem posições de construtos a serem discutidos, em um trabalho científico vinculado ao quadro teórico-metodológico 
da Lingüística. Em se tratando da sociolingüística quantitativa e da geolingüística monodimensional, a quantificação caracteriza tais subáreas. A cartografia é um diferencial quando se discute geolingüística. Já quando se discute o perfil do informante, aquela prefere o da zona urbana; e esta, o da zona rural, porque os fundamentos são diferentes.

O Banco de dados VARSUL, resultante da execução do projeto Variação Lingüística Urbana na Região Sul do Brasil, foi implementado pelas seguintes instituições: Universidade Federal do Rio Grande do Sul - UFRGS, Universidade Federal de Santa Catarina - UFSC e Universidade Federal do Paraná - UFPR. O projeto tem como meta armazenar e colocar à disposição dos pesquisadores interessados amostras de realizações da fala de habitantes enraizados em áreas urbanas sócio-culturalmente representativas de cada um dos três estados da Região Sul do Brasil. Em julho de 1996, prevê-se que esse banco contenha amostras representativas da fala de habitantes de 12 cidades, quatro em cada estado da Região Sul, num total de 96 entrevistas por estado, e 288 no acervo do Banco de Dados VARSUL. Trata-se de um trabalho realizado dentro dos postulados da sociolingüística variacionista, que pretende fornecer subsídios para estudos da variação lingüística da região (VARSUL, meio eletrônico) (1).

Este estudo deriva do interesse básico pelo português em sua historicidade, orientando a pesquisa para uma etnografia da variação espacial. Levantamentos dessa natureza privilegiam o léxico - confluência de língua e cultura, coletado mediante a aplicação sistemática de um questionário, através do qual se assegura uma base de comparação entre os dados recolhidos nos diversos pontos de inquérito. São inquiridos informantes que tenham experiência da economia rural, razão pela qual se prioriza a escolha de informantes adultos, do sexo masculino. E para que se possa estabelecer áreas lingüísticas, é necessário alcançar certa densidade espacial, vale dizer, o número de pontos de inquérito deve ser representativo em relação ao território sob estudo. Constata-se, assim, nesse gênero de levantamento, uma opção clara pelo léxico e pela horizontalidade (ALERS, 2002, v. 1: 17) (2).

A sociolingüística quantitativa olha a mudança lingüística a partir da norma-padrão, o que constitui a referência. Enquanto a geolingüística monodimensional observa a mudança lingüística a partir das diferenças dialetais regionais. Dito de maneira mais clara: comparam-se os variados falares, considerando o espaço, ou como os falantes de uma região falam diferente dos falantes de outra região.

O Projeto VARSUL (Variação Lingüística Urbana na Região Sul) foi constituído oficialmente em 1990 e visa à instalação de um Banco de Dados lingüísticos a partir da documentação do português falado nas áreas urbanas lingüisticamente representativas dos estados do Paraná, Santa Catarina e Rio Grande do Sul. Sua realização 
fica a cargo de uma equipe multi-institucional, da qual participam professores-pesquisadores vinculados a quatro instituições; Universidade Federal do Paraná, Universidade Federal de Santa Catarina, Universidade Federal do Rio Grande do Sul e a Pontifícia Universidade Católica do Rio Grande do Sul. Trata-se de um trabalho realizado dentro dos postulados da Sociolingüística Variacionista, que pretende fornecer subsídios para estudos de variação lingüística da região sul do Brasil. A coleta de dados foi iniciada em 1990 e se estende até hoje. As Universidades mencionadas possuem cópias completas do acervo total do banco, que podem ser consultadas, respeitando o regimento interno do mesmo (VARSUL, meio eletrônico) (1).

O ALERS concentra-se também na região sul, porém a localização geográfica é primordial e acredita-se que há um falar sulista particular, assim como há o falar carioca, o paulista, etc. Altenhofen (2002: 115), ao apresentar o objetivo de seu trabalho, explicita a necessidade fundamental de mapear o português falado numa determinada região brasileira:

Constitui o objetivo, a seguir, apresentar um conjunto de hipóteses acerca da delimitação de áreas lingüísticas significativas da variação diatópica do português falado na região sul do Brasil. Tais hipóteses, que prefiro chamar assim devido à falta de uma comprovação maior envolvendo uma base de mapas e fenômenos mais ampla, são uma tentativa de sintetizar os resultados de análises prévias dos mapas fonéticos e morfossintáticos produzidos até o momento pelo Atlas Lingüístico-etnográfico da Região Sul do Brasil (ALERS). (2)

O bilingüismo é posto em discussão no ALERS: o falante monolíngüe em português e o bilíngüe em português e em uma língua imigrante (italiano, alemão....).

... devemos distinguir entre português de falantes nativos e português de falantes bilíngües. Sendo este último aprendido em via de regra como segunda língua, podemos supor, nele, a presença de uma série de elementos da língua materna. Trata-se, assim, de um português de interferência. Em contrapartida, o português de contato segue, a meu ver, um critério geolingüístico; ele engloba uma variedade diatópica que pode ser falada tanto por bilíngües quanto por monolíngües (Altenhofen 2000: 74) (2).

Questões histórico-sociais também são discutidas quando se produz conhecimento em geolingüística monodimensional, diferente da sociolingüística quantitativa, que se limita às variáveis lingüísticas, como foi percebido nos trabalhos aqui analisados, apesar de se argumentar que o social interfere na mudança lingüística. 
Ao delimitar áreas lingüísticas, está-se delimitando, hipoteticamente, também fatores extralingüísticos determinantes dessas áreas, em virtude da probabilidade de correlação existente entre "a variedade do português em estudo" e "os traços extralingüísticos do meio geográfico", tais como origem e constituição étnica da população, atividades econômicas, densidade demográfica e redes de comunicação, migrações históricas, graus de isolamento e de urbanização, características do espaço em termos de relevo, vegetação e hidrografia, entre outros. Na região sul do Brasil, tem-se uma pluralidade social, cultural e geofísica rara que lhe confere um status particular no estudo do português brasileiro. (Altenhofen 2002:121-122) (2).

A geolingüística monodimensional incorpora, à medida do possível, como se observou nos trabalhos analisados, os aspectos sociais em suas análises, porque argumenta que eles atuam na constituição identitária dos sujeitos falantes. Já a sociolingüística quantitativa lida com as questões sociais como variáveis mensuráveis, limitando-se à descrição das tabulações feitas e posiciona, político-ideologicamente, tal descrição como suficiente para a explicação das mudanças lingüísticas.

\section{Considerações Finais}

Neste trabalho, mais precisamente, percebe-se que as formas de representar a língua possibilitam traçar — porém de forma provisória, não constituindo a verdade absoluta - a figura do informante na sociolingüística quantitativa e na geolingüística monodimensional. Conforme as três concepções de identidade de Hall (2003), o informante das subáreas da lingüística acima se fundamenta na idéia de interação, em que há a fragmentação da centralidade única, segundo a identidade de base essencialista, em dois pólos ou extremos. O informante configura-se num sujeito de base interacionista, porque sua voz é silenciada quando se consideram as posturas político-ideológicas reivindicadas por cada subárea. Posicionar a língua como um objeto de estudo heterogêneo e variável, é representá-la de modo que seja fruto daquilo que o informante, o falante, diz/fala quando é inquirido. No instante em que o falante é entrevistado, ele assume uma posição político-ideológica de informante, de produtor de falas/dizeres que apontam, conforme as políticas de representação da sociolingüística quantitativa e da geolingüística monodimensional, a mudança lingüística, sendo, assim, possível representar a língua como heterogênea e variável. Tal representação ocorre se houver uma política identitária específica para o sujeito falante. 
De um modo geral, o informante não constitui um construto, via linguagem, que representa o falante de uma língua cujas mudanças, em seu interior, são posicionadas como objeto de estudo. Isto é, em meio às políticas de representação da sociolingüística quantitativa e da geolingüística monodimensional, o informante não é visto como um sujeito que está no lugar de outro, aquele que diz em nome de outro. Questões sociais em torno do informante são trazidas aos trabalhos analisados anteriormente, no entanto não se aborda a subjetividade como um problema políticoideológico. Limita-se tal problema a uma questão lingüístico-social. Tanto no âmbito da sociolingüística quantitativa quanto na geolingüística monodimensional, a língua é um objeto de estudo constituído na heterogeneidade. Trata-se de variações cuja regularidade é identificável por meio de uma quantificação: a ordem que se quantifica.

Apesar dessas subáreas da Lingüística questionarem duas idéias fundamentais chomskyanas, a representação da comunidade lingüística como se fosse homogênea e a do falante como um ouvinte ideal, os procedimentos metodológicos utilizados remetem-se à quantificação e à separação do objeto de investigação do meio de produção: a comunidade e os falantes. A concepção de língua como um objeto heterogêneo é uma representação construída no bojo das subáreas em questão, que, em princípio, parece constituir uma ruptura em relação aos trabalhos chomskyanos. Contudo, a predileção pela quantificação das variações lingüísticas, manifestada tanto pelo inquiridor sociolingüista quantitativo quanto pelo inquiridor geolingüista monodimensional, desencadeia o silenciamento do sujeito falante para que as quantificações (os dados) falem em seu nome. Ou seja: emudece-se o sujeito falante, a partir do momento em que seu dizer não mais interessa ao pesquisador, para dar voz àquilo que é tido como mudo: as quantificações ou os números.

Assim, os interesses em prol da consolidação tanto da sociolingüística quantitativa como da geolingüística monodimensional como subáreas da Lingüística atuam justamente nesse processo, a fim de validar um estudo a respeito da variação lingüística como científico. Por trás de diferentes articulações no interior dessas subáreas, há interesses político-ideológicos, que influenciam na maneira de conceber o objeto de estudo, de lidar com o sujeito falante e com sua fala. Não é qualquer variação lingüística que interessa: para a sociolingüística quantitativa, a variação tem como referência a norma-padrão, no interior do sistema heterogêneo; enquanto, para 
a geolingüística monodimensional, a variação é tratada como tal quando está relacionada com o espaço geográfico.

Com base nas discussões arroladas e desenvolvidas, neste trabalho, pode-se concluir que interessam tanto à sociolingüística quantitativa quanto à geolingüística monodimensional apenas as práticas identitárias concordantes com seus propósitos de investigação: a assunção identitária do falante como informante de determinados dizeres, que refletem as ocorrências lingüísticas classificadas como mudanças ou variações. Portanto, a ida do pesquisador a campo, para a coleta de dados, segue a formatação de uma política de representação em que o conceito de variação, na língua investigada, constitui um construto pré-estabelecido, pré-julgado.

Para encerrar, é necessário retomar a seguinte pergunta de Rajagopalan (1998: 21): "É chegada a hora para uma reconsideração radical?", pois ainda, em se tratando dos estudos lingüísticos, se constrói uma política excludente das práticas identitárias dos sujeito falante.

Recebido em maio de 2007. Aprovado em outubro de 2007. E-mail: belborges1@hotmail.com

\section{REFERÊNCIAS BibLIOGRÁFICAS}

Atlas Lingüístico-etnográfico da Região Sul do Brasil (ALERS). 2002. Organização de Walter

Koch, Mário Silfredo Klassmann e Cléo Vilson Altenhofen. Porto Alegre; Florianópolis; Curitiba: Ed. UFRGS; Ed. UFSC; Ed. UFPR. v. 1. Introdução; v. 2. Cartas fonéticas e morfossintáticas.

Altenhofen, Cléo Vilson. 2000. O português em contato com as línguas imigrantes no Sul do Brasil. In: Gärtner, Eberhard; Hundt, Christine; Schönberger, Axel (Eds.) Estudos de Geolingüústica do Português Americano. Frankfrut am Main: TFM. p. 71-93. 2002. Áreas lingüísticas do português falado no sul do Brasil: um balanço das fotografias geolingüísticas do ALERS. In: Vandresen, Paulino (Org.). Variação e Mudança no Português Falado na Região Sul. Pelotas: EDUCAT. p. 115-145. 
2004. Política lingüística, mitos e concepções lingüística em áreas bilíngües de imigrantes (alemães) no Sul do Brasil. RILI II (Revista Internacional de Lingüística Iberoamericana). 1 (3): 83-93.

Bauer, Martin W.; Gaskell, George (Eds.). 2005. Pesquisa qualitative com textos, imagem e som: um manual prático. Tradução de Pedrinho A. Guareschi do título em inglês Qualitative researching with text, image and sound: a practical handbook. 4. ed. Petrópolis, RJ: Vozes.

Bauman, Z. 1997. Ética Pós-moderna. Tradução de J. R. Costa. São Paulo: Paulus.

. 1998a. Introdução. O mal-estar - moderno e pós-moderno. In: . O Mal-estar da Pós-modernidade. Tradução de M. Gama e C. M. Gama. Rio de Janeiro: Zahar. p. 7-11. 1998b. Pósfácio: a última palavra - e ela pertence à liberdade. In: _. O Mal-estar da Pós-modernidade. Tradução de M. Gama e C. M. Gama. Rio de Janeiro: Zahar. p. 246 - 257. . 2000. Em busca do espaço público. In: . Em Busca da Política. Tradução de M. Penchel. Rio de Janeiro: Zahar. p. 17-64.

Borges, Maria Isabel. 2004. O Jogo Ético-político nos Quadrinhos Editados em "O Pasquim". Uberlândia: Programa de Pós-graduação em Mestrado em Lingüística da Universidade Federal de Uberlândia (UFU). 179 p. (Dissertação de Mestrado em Lingüística).

Guattari, F.; Rolnik, S. 1986. Micropolítica. 2. ed. Petrópolis: Vozes.

HaLl, S. Identidade cultural e diáspora. 1996. Revista do Patrimônio Histórico e Artístico Nacional, n. 24: 68-75.

2000. Quem precisa de identidade. In: SILVA, T. T. da (Org. e trad.); Hall, S.; Woodward, K. Identidade e Diferença. Petrópolis: Vozes. p.103-133. 2003. A Identidade Cultural na Pós-modernidade. Tradução de T. T. da Silva e G. L. Louro. 7. ed. Rio de Janeiro: DP\&A.

Hinskens, F.; Hout R. V; W. Leo Wetzels. 2000. Um balanço de dados e teoria no estudo da variação e da mudança fonológica. Letras de Hoje. Porto Alegre, mar., v. 35, n. 1: 18-19.

LoPeS DA SiLva, Fábio Luiz. 2001. A arbitrariedade que não se encontra. Letras. Curitiba: Ed. da UFPR. jul./dez. n. 56: 291-300.

Margotti, Felício Wessling. 1991. Projeto número 19: Alternância do gênero em três comunidades catarinenses etnicamente distintas. In: Votre, Sebastião; Margotti, Felício W.; Vandresen, Paulino (Coords.). Cadernos de Pesquisa no Projeto VARSUL. Caderno 1: Projetos individuais. 
Primeiro Seminário de Pesquisas no Projeto Variação Lingüística Urbana na Região Sul. Florianópolis: Departamento de Língua e Literatura Vernáculas, Centro de Comunicação e Expressão, Universidade Federal de Santa Catarina. p. 169-177.

. 2004a. Difusão Sócio-geográfica do Português em Contato com o Italiano no Sul do Brasil. Porto alegre: UFRGS. 330 p. (Tese de doutorado). 2004b. Sotacon: a fala do colono. Anais do $6^{\circ}$ Encontro CELSUL (Círculo de Estudos Lingüísticos do Sul). (meio eletrônico) ; Vieira, Hilda Gomes. 2006. Indicadores de áreas lexicais em Santa Catarina: subsídios para políticas de ensino de língua portuguesa. In: Görski; Edair M.; Coelho, Izete L. (Orgs.). Sociolingüística e ensino: contribuições para a formação do professor de língua. Florianópolis: Ed. da UFSC. p. 109-133.

Organon. 2000. Porto Alegre, 2000, v. 14, n. 28 e 29 (Estudos da língua falada). 272 p.

Peters, M. 2000. Pós-estruturalismo e Filosofia da Diferença. Tradução de T. T. da Silva. Belo Horizonte: Autêntica.

Rajagopalan, K. 1998. O conceito de identidade em Lingüística: é chegada a hora para uma reconsideração radical? Tradução de A. Pisetta. In: Signorini, I. (Org.). Lingua(gem) e Identidade. Campinas: Mercado das Letras; São Paulo: Fapesp. p. 21-45.

Rajagopalan, K. 2002. A construção de identidades e a política de representação. In: Ferreira, L. M. A.; Orrico, E. G. D. (Orgs.) Linguagem, identidade e memória social. Rio de Janeiro: DP\&A. p. 77-87. 2003. Por uma lingüística crítica. São Paulo: Parábola.

Rolnik, S. 1997. Toxicômanos de identidade: subjetividade em tempo de globalização. In: Lins, D. S. (Org.) Cultura e Subjetividade. Campinas: Papirus. p. 19-24.

SiLVA, T. T. da. 2000. A produção social da identidade e da diferença. In: SILVA, T. T. da. (Org. e trad.); Hall, S.; Woodward, K. Identidade e Diferença. Petrópolis: Vozes. p. 73-102.

Vazzata-Dias, Juçá Fialho. 2000. A concordância de número nos predicativos/particípios na fala do sul do Brasil - motivações extralingüísticas. Letras de Hoje. Porto Alegre, mar., v. 35, n. 1: 209228.

Variação Lingü̈stica Urbana na Região Sul do Brasil (VARSUL) Disponível em: < http://www.cce.ufsc.br/ varsul/index.htm>. Acesso em: novembro de 2006. 